\title{
Educação crítica: uma possibilidade de formação "ambientalista" para professores de educação física
}

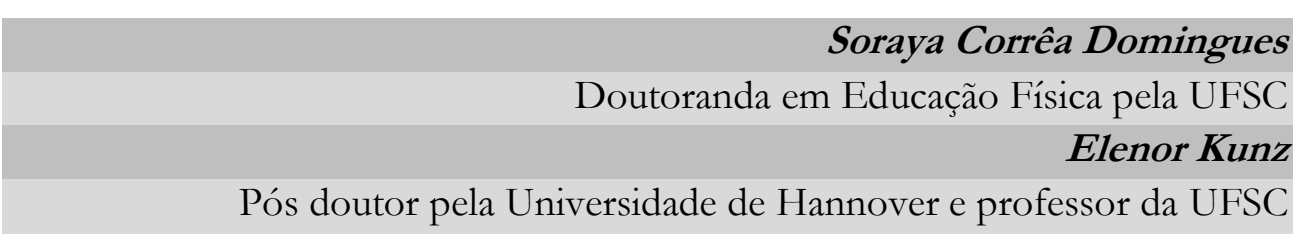

\section{Resumo}

As possibilidades de diálogo pedagógico entre os campos da Educação Ambiental e Formação Humana nos cursos de Educação Física é objeto deste estudo. Buscando revisar e evidenciar os princípios e objetivos construídos historicamente da Educação Ambiental e a atual realidade da formação de professores, identificando os limites e possibilidades para a construção de uma proposta crítica pedagógica que altera a lógica na Formação de Professores em Educação Física a partir do tripé ensino, pesquisa e extensão e a Educação Ambiental.

Palavras-Chave: Educação Ambiental; Educação Física; Formação de Professores.

\begin{abstract}
The possibilities pedagogical of the dialogue between the fields of Human Environmental Education and Training courses in Physical Education is an object of this study. The objective is review and clear the principles and objectives of environmental education, identifying the limits and possibilities for building critical pedagogical proposal amending the logic in the courses of the physical education from the triad education, research and outreach and environmental education.
\end{abstract}

Keywords: Environmental Education; Physical Education; Teacher Training. 


\section{Introdução}

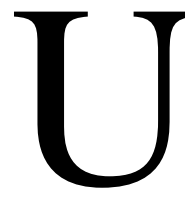

ma das características marcantes na modernidade é a aliança entre a ciência e o processo produtivo da indústria. Essa articulação entre a indústria e a ciência resultou no progresso científico, crescimento da mobilidade pessoal, crescimento da produção industrial, vertiginosa ampliação dos assentamentos humanos, nas cidades, determinando amplas e profundas mudanças nas relações sociais e econômicas que geram, por fim, o processo de destruição ambiental, como: efeito estufa; buraco na camada de ozônio; alterações na superfície da terra; exacerbações das mudanças climáticas; desflorestamento; queimadas; erosão do solo; areificação/ desertificação; destruição de habitats; perda da biodiversidade; poluição; escassez de água potável; erosão e perda da diversidade cultural e exclusão social. Segundo Dias (2001), esses são elementos que geram a necessidade de parar e pensar sobre as relações estabelecidas entre o ser humano e natureza e pela complexidade desta temática nos diversos espaços de formação humana com parâmetros na educação ambiental.

Neste sentido, este texto buscou analisar as possibilidades de relacionar os parâmetros de uma formação ambientalista como proposta crítico pedagógico na formação de professores de Educação Física. Inicialmente abordamos aspectos da concepção crítica de Educação Ambiental, posteriormente destacamos alguns limites e possibilidades da Educação Física para desenvolver uma formação ambientalista.

Estamos chamando de formação ambientalista o processo pedagógico que tem como objetivo a compreensão do meio ambiente enquanto um tempo espaço no qual o ser humano participa, constrói, age e transforma. Por isso, neste texto, falar de formação ambientalista está mais associado a um processo de conscientização ambiental do que ao ensino de conteúdos específicos sobre a natureza.

Encontramos diretrizes pedagógicas da formação ambientalista na Educação Ambiental que nos auxilia a pensar o processo de formação em 
Educação Física. Porém, chamamos atenção que o conceito de Educação Ambiental não é único, existem vários, cada um deles com metodologias e objetivos diferenciados. O Ministério do Meio Ambiente publicou em 2004 uma síntese sobre a diversidade da Educação Ambiental no Brasil, de acordo com esta publicação, estamos, neste texto, trabalhando com o conceito de Educação Ambiental crítica, pois consideramos que o processo educativo da formação ambientalista deve buscar a superação de problemáticas identificadas na realidade, pela organização de dois elementos fundamentais: o trato com o conhecimento, e a forma ou metodologia de organização deste conhecimento.

Neste sentido, a Educação Ambiental pode representar uma possibilidade de organizar a formação humana para educar por/ para/ pela práxis, buscando a conscientização do ser estar no mundo, de modo dialético. Abre possíveis caminhos para revolucionar as relações entre ser humano e natureza. Pois na perspectiva crítica, o processo de formação humana está marcado historicamente por uma herança da educação que apreende e explica o real dividido em partes, sem conexões entre si, sejam elas contingentes ou necessárias. Neste sentido, questionamos: Se o objetivo da Educação Ambiental é formar o indivíduo, que possa reconhecer, compreender e mudar o real concreto nas estruturas econômicas, sociais e culturais, então, não seria necessário propor um processo de formação que altere a lógica do trato com o conhecimento e mudar a forma com a qual o ser humano se relaciona com o mundo e consigo mesmo? Tentaremos responder esta pergunta pensando especificamente na formação de professores a partir de contribuições da Educação Ambiental crítica.

\section{Compreendendo os limites e possibilidades para a formação}

As atuais diretrizes da Educação Ambiental ${ }^{1}$ nos indica dois pontos sobre forma e objetivo que podem contribuir com uma formação em

\footnotetext{
${ }^{1}$ PCN - BRASIL, Secretaria de Educação Fundamental. Parâmetros curriculares nacionais: introdução aos parâmetros curriculares nacionais / Secretaria de Educação Fundamental. Brasília: MEC/SEE, 1997.
} 
Educação Física ambientalista. Quanto a forma, a Educação Ambiental deve ser trabalhada de modo transversal e interdisciplinar, pois parte do pressuposto que existe uma relação complexa e ecológicas entre o ser humano e a natureza. E quanto aos objetivos, ela busca a emancipação humana para transformação social, valorizando o processo educativo para a conscientização. Esta conscientização é construída pela ação-reflexão-ação no mundo, valorizando a cultura através de um movimento dialógico que entende, produz e reproduz sentidos e significados.

Portanto pensar em trabalhar Educação Ambiental a partir de sua forma e de seu objetivo implica em analisar a realidade dos cursos de professores em Educação Física. Buscando entender quais são os limites que a realidade desses cursos apresenta diante da proposta da Educação Ambiental e indicar as possibilidades de superação.

Alguns limites da Educação Física são também próprios das licenciaturas em geral. Destacaremos alguns desses limites no documento final da ANFOPE (2004) $)^{2}$ : cursos burocráticos, no que diz respeito ao funcionamento, muitas disciplinas de fundamentação teórica, poucas disciplinas optativas, pouca flexibilização e atualização dos currículos, desarticulação de conteúdos curriculares, muitos pré-requisitos, problemas com algumas disciplinas lotadas em outros departamentos, desatualizarão metodológica, pouco envolvimento de professores nas questões de currículo, dificuldade para elaboração de projetos pedagógicos para os cursos, embates quanto a definição do perfil profissional, número pequeno de projetos de extensão, a dicotomia teoria-prática e o fosso entre a realidade e a produção do conhecimento científico.

A realidade da Educação Física apresenta além destas características outras que são específicas. Das quais chamamos atenção para a fragmentação da formação em Bacharelado e Licenciatura, o que para alguns autores como Taffarel (2007) e Rezer (2007) é uma forma de fragmentação e desarticulação da classe dos profissionais de Educação

\footnotetext{
${ }^{2}$ Este documento foi detalhadamente analisado na Dissertação de Mestrado sobre Meio Ambiente e Formação de Professores de Soraya Corrêa Domingues defendida em 2005.
} 
Física. Na formação dos licenciados, os currículos acentuam a dicotomia mente-corpo, trabalho manual e intelectual, aspectos ainda não superados nem mesmo pela última reformulação curricular.

Apresentamos essa realidade das licenciaturas e da Educação Física como um ponto de partida para pensar as possibilidades de superação pedagógica. Neste sentido o trabalho anterior de Domingues (2005) sobre cultura corporal e formação de professores apresenta uma proposta de Atividade Curricular em Comunidade na Universidade que estrutura a organização pedagógica a partir da indissociabilidade entre ensino, pesquisa e extensão. Na nossa análise esta proposta de indissociabilidade contribui para pensar em uma formação ambientalista crítica nos cursos de Educação Física. Na indissociabilidade pode-se pensar em espaço-tempo pedagógico para organização de conteúdos e produção do conhecimento em outra lógica científica, não mais pautada na fragmentação do conhecimento, mas sim na relação cotidiana com a realidade.

Outra possibilidade está na própria política pública de educação. Nos documentos oficiais, como PCN's e diretrizes gerais sobre Educação Ambiental $^{3}$, há uma indicação da forma transdisciplinar e interdisciplinar no trato com o conhecimento nos currículos. Oferece, portanto, legalmente, um caminho para construir o currículo, não mais baseado na pedagogia dos conteúdos fragmentados e isolados, mas sim na lógica da complexidade ${ }^{4}$ ambiental para a formação de professores ampla omnilateral.

Neste sentido, a proposta de formar para liberdade e emancipação depende do desenvolvimento de espaços pedagógicos a partir de atividades de ensino, pesquisa e extensão, a partir da construção de um currículo flexível, que supere a dicotomia teoria/ prática, e valorize a formação

\footnotetext{
${ }^{3}$ Documento disponível no Ministério do Meio Ambiente, diz respeito às diretrizes gerais sobre Educação Ambiental no Brasil.

${ }^{4}$ Kunz analisa a educação Infantil e a necessidade de liberdade e criatividade para o se movimentar humano nesta fase de vida e a partir de estudos da psicanálise ele traz Merleau Ponty que analisa os Complexos da criança e a necessidade de compreensão desses complexos para estabelecer uma educação emancipatória, que traz os mesmo princípios da educação ecológica. Mas adiante faremos uma abordagem sobre as possíveis ralações entre o se Movimentar humano e a educação ambiental para os currículos de educação física.
} 
profissional omnilateral, considerando a docência como a base do perfil do educador ${ }^{5}$. Passando a ter como estrutura da organização do trabalho pedagógico a formação humana no mundo vivido e experimentado.

Compreendemos a extensão como um espaço institucional e indissociável, possível de construir um ambiente significativo para a formação humana que considera os processos educativos, culturais e científicos, articulados pelo Ensino e Pesquisa de forma que viabiliza a relação transformadora entre Universidade e Sociedade, entre o mundo e a formação. Além de oferecer o espaço formal para a formação de professores, ela é uma via de mão-dupla, com trânsito assegurado à comunidade acadêmica, que encontra, na sociedade, a oportunidade de elaboração da práxis do conhecimento acadêmico. No retorno à Universidade, docentes e discentes aprendem submetidos à reflexão teórica, o que é construído junto àquele conhecimento, numa ação-reflexão-ação no mundo.

Os princípios estabelecidos pelo Plano Nacional de Extensão ${ }^{6}$ também oferecem alguns elementos para articular o conhecimento da Educação Física e a Educação Ambiental, são eles: a ciência, a arte e a tecnologia baseadas nas prioridades do local, da região, do país; a compreensão de uma universidade sensível aos seus próprios problemas e apelos quer através dos grupos sociais com os quais interage, ou através das questões que surgem de suas atividades próprias de ensino, pesquisa e extensão; a proximidade entre a universidade e movimento humano e social, priorizando ações que visem à superação das atuais condições de desigualdade e exclusão existentes no Brasil; deve entender a população como objeto e sujeito de suas pesquisas, tendo ela, portanto, pleno direito de acesso às informações resultantes dessas pesquisas; a prestação de serviços representa produto de interesse

\footnotetext{
${ }^{5}$ De acordo com críticas sobre a reformulação curricular da ANFOPE.

${ }^{6}$ O movimento pela extensão toma fôlego e promove em 1987 I Encontro Nacional de PróReitores de Extensão das Universidades Públicas Brasileiras trazendo a discussão para primeiro plano e garantindo a construção do Fórum de Pró-Reitores de Extensão das Universidades Brasileiras. Inaugura-se, assim, um processo de revisão do conceito da extensão e de construção coletiva de uma política de extensão para as universidades públicas, num nível diferenciado.
} 
acadêmico, encarada como um trabalho social, que se constitui a partir da realidade e sobre a realidade vivida. Produzindo conhecimentos que visa à transformação do próprio ser e social; a atuação junto ao sistema de ensino público pode se constituir em uma das diretrizes prioritárias para o fortalecimento da educação através de contribuições técnico-científicas e colaboração na construção e difusão dos valores da cidadania.

Esses princípios proporcionam a criação de espaços de atividades curriculares para além da grade curricular, um espaço de criação e experimentação que possibilita conhecer, apreender, sistematizar e superar problemáticas da realidade. É um processo de resistência e continuidade no qual na Formação de Professores o maior entrave é reconhecer a indissociabilidade entre ensino, pesquisa e extensão como princípio educativo. É necessário que a experiência seja e faça parte da formação humana em todos os momentos do curso, permitindo experimentar desenhos curriculares em que a extensão e a pesquisa estejam inseridas não como apêndices curriculares opcionais, mas como práticas essencialmente pedagógicas, vinculadas visceralmente ao processo de formação para a emancipação humana.

Em Educação e Mudança, Kunz (2001), chama atenção para as influências da formação fragmentada e suas influências na prática pedagógica dos professores de Educação Física na escola. Considerando esta grande influência é que este estudo abre caminhos para pensar sobre problemáticas na formação de professores de Educação Física. Aproximando a teoria da prática, o mundo acadêmico do trabalho produtivo a partir de elementos como: produção compartilhada de conhecimento; compreensão do conhecimento como ferramenta de transformação; compreensão da necessidade de um enfoque multidisciplinar dos problemas da realidade (superando-se a visão fragmentada e fragmentária das disciplinas fechadas nos currículos); reflexão sobre temas significativos e significantes da realidade da Educação Física.

É neste cenário de mudanças e reestruturação que os princípios da Educação Ambiental crítica podem ser trabalhados para alterar a formação 
de professores em Educação Física. Compreendendo que uma das bases para entender as relações do corpo em movimento e sua cultura é sua relação com natureza. A Educação Física encontra aqui uma possibilidade de alterar a lógica no processo de formação. Com isso construir uma forma superadora de organizar os espaços pedagógicos a partir da articulação entre ensino, pesquisa e extensão, Educação Ambiental e Educação Crítica.

\section{Especificidades da formação de professores em educação física}

$\mathrm{Na}$ Educação Física os estudos críticos, buscam reconhecer o seu papel social. Eles propõem metodologias para tratar deste conteúdo na escola, reconstrói a história a partir de produções culturais brasileiras, debatem sobre epistemologia e propõem superação de antigas fragmentações como corpo/ mente. Esses estudos contribuíram e ainda contribuem para mudanças no campo de atuação da Educação Física, mas, apesar dessa produção de trabalhos publicados em congressos, revistas, encontros, fóruns, são perceptíveis que alguns dos limites apresentados não foram superados, como a: cisão entre teoria e prática da área, evidenciada por Taffarel (2007) no texto sobre Formação de Professores e tensões na luta de classes; a esportivização dos conteúdos, destacada por vários autores, inclusive Kunz (2001); e a fragmentação da classe dos professores de Educação Física com a cisão dos cursos de Bacharelado e Licenciatura, indicado por Rezer (2007).

Neste panorama da realidade dos cursos de Educação Física é que pensamos sobre uma lógica que articula os Princípios da Educação Ambiental e a forma indissociável da Extensão, Ensino e Pesquisa, capaz de compreender a dinâmica da complexidade ambiental a partir da aproximação com a realidade, o que significa formar para superar as fragmentações corpo e mente, teoria e prática, licenciatura e bacharelado.

Para nós pensar em uma formação ambientalista na Educação Física é indicar que existem possibilidades de mudanças na estrutura sócioeconômica que permite estabelecer outras relações entre o ser humano e a natureza, transformando-a sem destruí-la. Neste sentido o processo de 
formação em Educação Física pode contribuir com as suas especificidades. Portanto, o desafio deste texto foi pensar criticamente sobre a atual organização do processo pedagógico da formação, propondo, a partir desta atual organização mudanças para a formação de professores em Educação Física, tendo como meio e fim, a alteração das relações ser humano com ele mesmo, com o seu corpo.

Enquanto estrutura de organização pedagógica na Formação de Professores em Educação Física analisamos possibilidade da indissociabilidade entre ensino, pesquisa e extensão contribuir com a formação ambientalista. A seguir buscamos analisar dois pontos que está relacionado ao trato com o conhecimento na Educação Física a partir da perspectiva da Educação Ambiental Crítica: O primeiro é garantir conteúdos que proporcione ao estudante o contato com a sua realidade, e deste meio proporcionar possibilidades de interação com o corpo em movimento e com o mundo; O segundo é ter como pressuposto ontológico a compreensão do ser humano histórico e cultural, que se inter-relaciona com os outros e com a natureza, neste sentido, é preciso entender que o ser humano se relaciona com o mundo, que ele está no mundo. Este ser, estar e fazer é uma das possibilidades de se reencontrar e de se conscientizar de sua existência emancipando-se da sua atual alienação ${ }^{7}$.

O primeiro ponto é uma proposta de aprendizagem pela experimentação livre e criativa, que na Educação Física, pelo conceito do se movimentar $^{8}$, abre-se perspectiva para um redimensionamento e uma apreensão abrangente de campos de atuação pelo movimento dialógico com o mundo, construindo um campo de atuação não alienada dos participantes, estabelecendo relações de sentido e significado, transformando-se numa inter-relação dialética entre Subjetividade e Objetividade em movimento.

\footnotetext{
${ }^{7}$ Alienação no mundo do trabalho, no qual o corpo é alugado para outro fim fora de sim mesmo. Que é o trabalho manual da atual sociedade capitalista. Também estamos de alienação específica na educação física, de fragmentação corpo e mente, por exemplo.

${ }^{8}$ Conceito estudado por Elenor Kunz desde seus primeiros estudos no Mestrado e Doutorado até os dias de hoje.
} 
É neste processo que se reconhece o ser humano, como ele se representa no mundo, hoje, o que ele faz como ele transforma e como ele é. Estabelecendo aqui a relação de ensino-aprendizagem. A formação de sentido e significado é um dos processos mais importantes para a formação emancipatória com aproximação na realidade, busca-se vivenciar, experimentar e produzir cultura. Neste movimento o ser humano entra em contato com sua própria cultura, com o meio social que ele mesmo produz e com o que ele é, estabelece aqui a inter-relação com o mundo. E dessa forma entraremos já no segundo ponto.

Ao eleger a realização espontânea e ignorando os movimentos não problemtizados e já conhecidos, valoriza-se também movimentos que pertencem ao domínio do cotidiano, problematizando o conhecimento, a partir de elementos da cultura. A vivência e experiência na formação de professores, a partir da cultura do cotidiano, da história, proporcionam a participação no processo de autoconhecimento, desalienação, sem repetições de movimentos, mas, com criações livres. Pelo reconhecimento do seu meio próprio de se movimentar e de se expressar ele valoriza sua cultura e seus recursos de vida.

\section{Algumas conclusões}

A partir dessas considerações podemos concluir que na formação de professores em Educação Física, as possibilidades para alterar e transformar a organização com base em uma perspectiva ambientalista está relacionada a aproximação dos estudantes à realidade concreta, o que exige reorganização curricular, não do currículo formal, mas do currículo efetivamente construído, extensão, aliado a pesquisa para responder às problemáticas com aprofundamento teórico e ensino. Essas ações de extensão, ensino e pesquisa, lidam não mais com conteúdos, mas sim com a própria realidade no campo de trabalho da Educação Física, como expressões da cultura do movimento, danças, folguedos, jogos, brincadeiras entre outros, reconhecendo as multidimensões dessas expressões buscando construir o conhecimento de forma interdisciplinar. A interdisciplinariedade é vista 
como uma possibilidade de aproximação da Educação Física a práxis social e permite organizar os conteúdos de forma complexa e totalitária a partir de vivências e experiências no mundo. Esse agir e refletir no mundo apreende a permanente mudança e o caráter histórico da realidade problematizando como temas e conteúdos. A problematização de conteúdo é proporcionada por situações de criações comunicativas e explorativa do movimento, refletindo as condições sociais, históricas e culturais do movimento humano em geral. Estabelecendo criar-ação comunicativa ou ação reflexão ação, os processos de inter-relação com as problemáticas da realidade encontram-se formas de relacionar o corpo suas múltiplas dimensões e a natureza.

As possibilidades de uma formação ambientalista na Educação Física é uma proposta que pretende pensar a formação de professores a partir da interdisciplinar, da indissociabilidade do ensino, pesquisa e extensão e do trato com o conhecimento crítico. Portanto, compreendemos que as especificidades da Educação Física podem contribuir para mudar as atuais relações de destruição ambiental entre o ser humano e a natureza. E compreendemos que apesar deste texto trabalhar com alguns conceitos aparentemente distantes, sua relevância está na representação de um longo caminho para pensar outras formas de organizar os cursos de Licenciatura em Educação Física.

\section{Referências}

ANFOPE. Considerações das Entidades Nacionais de Educação - ANPEd, CEDES, ANFOPE e FORUNDIR. Sobre a Proposta de Resolução do CNE que instituiu Diretriz Curricular Nacional para o curso de pedagogia. 2004.

DIAS, G. F. Educação Ambiental. Princípios e Praticas. $6^{\circ}$ edição. Revisado e Ampliado pelo autor. São Paulo, Gaia, 2001.

DOMINGUES. S. C. Cultura Corporal e Meio Ambiente na Formação de Professores. 2005, 289 páginas. Dissertação de Mestrado do Curso de Pós-graduação em Educação da Faculdade de Educação, UFBA, Salvador, BA.

KUNZ, E. Educação Física. Ensino e Mudança. Ijuí, RS, Unijuí, 2001. 
REZER, R. As novas diretrizes curriculares a regulamentação e o processo de formação apontamentos para o campo da Educação Física Brasileira, Ricardo Rezer e Juarez Vieira do Nascimento, In: XV Congresso Brasileiro de ciências do Esporte II Congresso Internacional de Ciências do Esporte, 2007, Recife. Anais do Congresso Brasileiro de Ciências do Esporte. Pernabuco: UFPE, 2007. Acesso em < www.cbce.org.br $>20$ de dezembro de 2009.

TAFFAREL, C. Formação Humana e Formação de Professores: Contribuições para construção do projeto histórico socialista. Celi Taffarel e Solange Lacks. In: Anais do XV CONBRACE/ Colégio Brasileiro de Ciências do Esporte. Congresso Brasileiro de Ciências do Esporte, Recife, PE. Acesso em: www.cbce.org.br, 2007. 